\title{
COVID-19 and Pregnancy-Series of Cases and Review of Literature
}

\author{
Yassir Ait Benkaddour1, Ousmane Omar Bâ1, Bouchra Fakhir'1, Aboubacar Sidibé1, \\ Abderraouf Soummani', Ahmed Rhassane El Adib², Houssam Rebahi², Nadia El Idrissi Slitine ${ }^{3}$, \\ Fadl Mrabih Maoulainine ${ }^{3}$, Fatima Ezzahra Hazmiri ${ }^{4}$
}

\author{
${ }^{1}$ Department of Obstetrics and Gynecology, UHC Mohammed VI, Marrakesh, Morocco \\ ${ }^{2}$ Department of Maternity Anesthesia Intensive Care Unit, UHC Mohammed VI, Marrakesh, Morocco \\ ${ }^{3}$ Department of Pediatrics, UHC Mohammed VI, Marrakesh, Morocco \\ ${ }^{4}$ Department of Histology-Embryology-Cytogenic, UHC Mohammed VI, Marrakesh, Morocco \\ Email: baousmane2411@gmail.com
}

How to cite this paper: Benkaddour, Y.A. Bâ, O.O., Fakhir, B., Sidibé, A., Soummani, A., El Adib, A.R., Rebahi, H., El Idrissi Slitine, N., Maoulainine, F.M. and Hazmiri, F.E. (2021) COVID-19 and Pregnancy-Series of Cases and Review of Literature. Open Journal of Obstetrics and Gynecology, 11, 1397-1410.

https://doi.org/10.4236/ojog.2021.1110130

Received: September 18, 2021

Accepted: October 24, 2021

Published: October 27, 2021

Copyright $\odot 2021$ by author(s) and Scientific Research Publishing Inc. This work is licensed under the Creative Commons Attribution International License (CC BY 4.0).

http://creativecommons.org/licenses/by/4.0/

\section{(c) (i) Open Access}

\begin{abstract}
Objectives: To bring out the clinical, biological, and therapeutic aspects of pregnant women and women in the post-partum infected by the SARS COVID-19 in the University hospital of Marrakesh. To study the vertical transmission of the virus if it exists, and the impact on the newborn. Methods: It is a prospective observational study on women infected by COVID-19 virus admitted in the gynecology obstetrics department of the University hospital of Marrakesh during the period between March 1st and July 15th. Data collection was insured thanks to a customized form containing the medical history, clinical criteria, biological and, radiological findings as well as the treatment and maternal and neo-natal outcomes. Results: The clinical, biological and radiological presentation of COVID-19 infection in pregnant and post-partum women doesn't seem to be different from general population. Pregnant and postpartum women don't seem to be more at risk to develop severe features of the disease. Vertical transmission via placenta is possible. COVID-19 infection may cause premature labor, premature rupture of membranes, preeclampsia or fetal distress.
\end{abstract}

\section{Keywords}

COVID-19, Pregnancy, Post-Partum

\section{Introduction}

COVID-19 is a viral rapidly spreading pandemic resulting in a severe respiratory infection that can be fatal especially to patients who have preexisting conditions. 
There are limited case series reporting the impact of COVID-19 during pregnancy, and so their management is a challenge because of the insufficient data.

The aim of this study is to bring out the clinical, biological and therapeutic aspects of pregnant women and women in the post-partum infected by the SARS $\operatorname{COV} 2$, to study the vertical transmission of the disease if it exists, and also the impact of the disease on the offspring.

\subsection{Origin and Virology}

Novel coronavirus 2019 (COVID-19) also known as severe acute respiratory syndrome coronavirus 2 (SARS-CoV-2) is an enveloped, non-segmented positivesense RNA virus belonging to the beta-coronaviridae family [1].

It may have emerged in Hubei province in China as early as November, 2019, originating most likely from bat-associated coronavirus. The USA, Brazil and India are the countries currently most affected after Europe countries especially Italy and Spain [2].

Coronaviruses contain the largest genomes of all RNA viruses. They have helical nucleocapsids and an envelope that is derived from intracellular membranes. Electron micrographs show spikes sticking out of their surfaces (due to a large glycoprotein), leading to their name (corona = crown) [3].

The whole genome sequence of $\mathrm{nCoV}$-2019 has been decoded, and its genomic characterization has shown close homology with bat-derived severe acute respiratory syndrome (SARS)-like coronaviruses, bat-SL-CoVZC45 and bat-SLCoVZXC21. Structural analysis of the receptor binding site has confirmed that 2019$\mathrm{nCoV}$ binds with the same ACE 2 receptor protein as human SARS virus [2].

It has been shown that three human coronaviruses cause acute and severe maternal illnesses:

- MERS-CoV that causes Middle East Respiratory Syndrome (MERS).

- SARS-CoV that causes severe acute respiratory syndrome (SARS).

- SARS-CoV-2 that causes COVID-19 [4].

\subsection{Transmission}

There are two routes by which COVID-19 can be spread. The first is directly through close contact with an infected person (within 2 meters) where respiratory secretions can enter the eyes, mouth, nose or airways. The second route is indirectly via the touching of a surface, object or the hand of an infected person contaminated with respiratory secretions and subsequently touching one's own mouth, nose or eyes [5].

\subsection{Diagnosis}

Sars-cov-2 could be recovered on woman and newborns by real-time RT-PCR from nasal and throat swabs, sputum and feces of symptomatic patients but not from vaginal swabs, amniotic fluid, cord blood, neonatal blood or breast milk [6]. 
The sensitivity of real time RT-PCR testing varies from a site to another. It is around $63 \%$ in nasal swabs, $93 \%$ in bronchoalveolar lavages and $29 \%$ in feces [7].

In our study, all of the samples were from nasal swabs, which have a high percentage of false negatives. It pushed us to repeat the tests and to take more caution for symptomatic women with negative nasal swab.

The test should be done for any symptomatic woman or a woman in contact with an infected patient A contact is defined as any of the following:

- Providing direct care for Covid-19 patients without using proper protective equipment.

- Being in the same close environment as COVID-19 patient.

- Traveling in close proximity (within 1 - 2 meters) to a Covid-19 patient [8].

\subsection{Clinical Presentation in Pregnant Women}

- Although the review of the literature is limited, the clinical, biological and radiological presentation of COVID-19 infection in pregnant and post-partum women doesn't seem to be any different from general population.

- The majority of pregnant women only experience a mild cold, sometimes associated with cough, fever or dyspnea. Some may be asymptomatic carriers whereas others may experience a severe presentation of the disease with an acute respiratory distress syndrome requiring respiratory support and admission to intensive care unit [9]. Women who were treated in our facility were no different.

\section{Methods}

\subsection{Study Design and Patients}

It is a prospective observational study on women admitted in gynecology and Obstetrics department of the University hospital of Marrakesh, within a four and a half months' period (from $1^{\text {st }}$ of March to $15^{\text {th }}$ of July 2020) and who were tested positively for Covid-19 via nasopharyngeal RT-PCR after presenting respiratory symptoms or having a contact with an infected person. During that period, 51 suspected patients were tested and 11 of them were positive for COVID19.

\subsection{Data Collection}

After informed consent of all the patients, data collection was performed using a customized form containing medical history, clinical criteria, biological and radiological findings as well as the treatment and maternal and neonatal outcome.

Suspected patients were identified according to national definition (phase 2), a specific management protocol was established to reduce the risk of contagion. They were all isolated in a specialized obstetrics Covid-19 department, until the results of the nasopharyngeal samples were obtained.

The patients who were tested negative have been redirected to the obstetrics 
service, and the patients who were positive stayed in the COVID-19 department or in the intensive care unit, during a period of at least 14 days, receiving the necessary treatment and medical care, until the control of the RT-PCR was negative. Some of the patients were transferred from other hospitals.

Nasopharyngeal samples were obtained in the examination room, by the physician on call, using a CDC recommended kit. First the Pasteur Institute of Casablanca processed these samples, later local laboratory becomes in charge, performing an RT-PCR enhancing the viral RNA.

Other blood samples were taken including a blood count, $\mathrm{C}$ reactive protein and ferritin levels, liver and kidney function tests. Chest CT-scan was performed only in patients with severe respiratory signs.

A day 10 RT-PCR control was performed for all the patients.

The evolution was considered favorable when the symptoms of respiratory infection disappeared and the RT-PCR was negative. No control CT-Scan was performed.

The spontaneous labor and the usual C-section indications were respected, there were no particular indication related to COVID-19 apart from respiratory distress.

We have also analyzed a few samples of amniotic fluid, stool, placenta and breast milk from a few patients.

\subsection{Statistical Analysis}

Statistical analysis was performed using Excel program version 2019. Continuous variables were expressed in range, and categorical variables were expressed as number (percentage).

\section{Results}

\subsection{Clinical Characteristics and Symptoms}

Most of the admissions occurred in April. The duration of stay was on average of 17.45 days (Table 1 ).

The medium age of patients was $28 \pm 10$ years old. The majority of them $77 \%$ ( 9 cases) had no medical history. One of the patients had a history of previous C-section for severe preeclampsia. $72.72 \%$ (8 cases) had a contact with a known infected person. Most of Covid-19 infections occurred during the third trimester $54.54 \%$ ( 6 cases), 9.09\% during the second trimester (1 case), 18.18\% ( 2 cases) on the first trimester and $18.18 \%$ ( 2 cases) patients were infected in the post-partum period. The first registrated case was a patient admitted in maternity anesthesia intensive care unit at first for eclampsia complicated with Pres syndrome and kidney failure (Table 2).

Most of the patients experienced only mild symptoms with an Early Warning Score EWS below 4 (90.90\%). The most common symptoms were cough and headache (54.54\%), followed by myalgia (45.45\%) fever (36.36\%), anosmia (36.36\%) and diarrhea $(9.09 \%)$. 
Only one woman (9.09\%) presented severe symptoms according to EWS and was admitted in intensive care unit (ICU). She had a history of an early C-section, and experienced a premature labor and early rupture of the membranes which resulted in another C-section (Table 3).

\subsection{Biological and Imaging Results}

Regarding biological results, 9.09\% (1 case) of the patients had elevated white blood cells, $45.45 \%$ (5 cases) had anemia, $45.45 \%$ (5 cases) had an elevated

Table 1. Date of admission and duration of patient stay.

\begin{tabular}{cccccccccccc}
\hline Patient & $\mathbf{1}$ & $\mathbf{2}$ & $\mathbf{3}$ & $\mathbf{4}$ & $\mathbf{5}$ & $\mathbf{6}$ & $\mathbf{7}$ & $\mathbf{8}$ & $\mathbf{9}$ & $\mathbf{1 0}$ & $\mathbf{1 1}$ \\
\hline Date of admission & $4 / 3 / 20$ & $3 / 4 / 20$ & $12 / 4 / 20$ & $16 / 4 / 20$ & $26 / 4 / 20$ & $27 / 4 / 20$ & $28 / 4 / 20$ & $2 / 6 / 20$ & $2 / 6 / 20$ & $10 / 6 / 20$ & $14 / 6 / 20$ \\
Duration of stay & 21 days & 16 days & 19 days & 16 days & 15 days & 13 days & 25 days & 13 days & 17 days & 20 days & 17 days \\
\hline
\end{tabular}

Table 2. Clinical and obstetrical characteristics of patients.

\begin{tabular}{|c|c|c|c|c|c|c|c|c|c|c|c|}
\hline \multicolumn{12}{|c|}{ Patients clinical characteristics } \\
\hline Patient & 1 & 2 & 3 & 4 & 5 & 6 & 7 & 8 & 9 & 10 & 11 \\
\hline Age (in years) & 28 & 21 & 38 & 19 & 30 & 26 & 28 & 34 & 18 & 19 & 39 \\
\hline Medical history & - & - & - & $\begin{array}{l}\text { Surgery for } \\
\text { cervical } \\
\text { hernia }\end{array}$ & $\begin{array}{l}\text { Early C-section at } \\
28 \text { weeks for severe } \\
\text { preeclampsia }\end{array}$ & - & - & - & - & - & - \\
\hline $\begin{array}{l}\text { Contact with } \\
\text { infected } \\
\text { patient }\end{array}$ & No & No & Yes & Yes & No & Yes & Yes & Yes & Yes & Yes & Yes \\
\hline $\begin{array}{c}\text { Gestational age on } \\
\text { admission }\left(1^{\text {st }}, 2^{\text {nd }},\right. \\
3^{\text {rd }} \text { trimester or } \\
\text { postpartum })\end{array}$ & Post-partum & $3 \mathrm{~T}$ & $1 \mathrm{~T}$ & $3 \mathrm{~T}$ & $3 \mathrm{~T}$ & $2 \mathrm{~T}$ & $1 \mathrm{~T}$ & $3 \mathrm{~T}$ & $3 \mathrm{~T}$ & $3 \mathrm{~T}$ & Post-partum \\
\hline $\begin{array}{c}\text { Pregnancy } \\
\text { complications }\end{array}$ & $\begin{array}{c}\text { Eclampsia, Press } \\
\text { syndrome and } \\
\text { renal failure }\end{array}$ & No & No & No & $\begin{array}{c}\text { Premature rupture } \\
\text { of membranes and } \\
\text { early labor }\end{array}$ & No & No & No & No & $\begin{array}{c}\text { Preeclampsia } \\
\text { and HELLP } \\
\text { syndrome }\end{array}$ & No \\
\hline
\end{tabular}

Table 3. Patients clinical symptom.

\begin{tabular}{ccccccccccccccccc}
\hline & \multicolumn{7}{c}{ Clinical symptoms } \\
\hline Patient & $\mathbf{1}$ & $\mathbf{2}$ & $\mathbf{3}$ & $\mathbf{4}$ & $\mathbf{5}$ & $\mathbf{6}$ & $\mathbf{7}$ & $\mathbf{8}$ & $\mathbf{9}$ & $\mathbf{1 0}$ & $\mathbf{1 1}$ \\
\hline Fever & Yes & Yes & No & No & Yes & No & No & No & Yes & No & No \\
Caugh & Yes & Yes & Yes & Yes & Yes & No & No & No & Yes & No & No & No \\
Dyspnoea & Yes & Yes & No & No & Yes & No & No & No & No & No & No \\
Anosmia & No & No & Yes & Yes & No & No & No & Yes & No & No & Yes \\
Diarrhea & No & No & No & No & No & No & No & No & Yes & No & No \\
Myalgia & Yes & Yes & No & Yes & No & No & No & No & Yes & No & Yes \\
Headache & Yes & No & Yes & Yes & No & No & No & No & Yes & Yes & Yes \\
Early warning score (EWS) & $<4$ & $<4$ & $<4$ & $<4$ & $>4$ & $<4$ & $<4$ & $<4$ & $<4$ & $<4$ & $<4$ \\
\hline
\end{tabular}


C-reactive protein and only 9.09\% (1 case) had an elevated ferritin.

No patient had hepatic dysfunction and only one had a renal failure complication of eclampsia (first case) for which she received hemodialysis (Table 4).

CT-thoracic Scan has been performed for 3 patients (27.27\%). Among them, two had typical signs of viral infection (Table 5).

\subsection{Medical Treatment}

$36.3 \%$ (4 cases) of women received Azithromycin $500 \mathrm{mg}$ at day 1 and $250 \mathrm{mg}$ from day 2 to 7 according to the national protocol. One patient received ceftriaxone 2 g per day during 7 days. 36.3\% (4 cases) of the patients were treated with hydroxychloroquin (Plaquenil) with a dosage of $200 \mathrm{mg}$ twice a day during 10 days. Namely that Ceftriaxone was given to a patient because of the severity of her infectious syndrome, she also had premature rupture of membranes. $18.18 \%$ ( 2 cases) received the association Lopinavir/Ritonavir $400 \mathrm{mg} \times 2$ per day. All the patients received vitamins and LMWH $0.4 \mathrm{ml}$ per day. Only $18.18 \%$ ( 2 cases) needed oxygen support (Table 6).

$36.36 \%$ ( 3 cases) of the patients are still pregnant to date. $18.18 \%$ ( 2 cases) gave vaginal birth after negativation of the RT-PCR, 36.3\% (4 cases) underwent a C-section for obstetrical indication, meanwhile $18.18 \%$ (2 cases) were seen in the post-partum period. The indications for C-section were Fetal distress (2 cases), Preeclampsia (1 case) and early labor with premature membranes rupture with a history of a previous C-section at 7 months pregnancy [10]. Note that in recent weeks some samples of amniotic fluid, stool, placenta and breast milk have been

Table 4. Patients biological results.

\begin{tabular}{|c|c|c|c|c|c|c|c|c|c|c|c|}
\hline \multicolumn{12}{|c|}{ Biological results } \\
\hline Patient & 1 & 2 & 3 & 4 & 5 & 6 & 7 & 8 & 9 & 10 & 11 \\
\hline Hyperleukocytosis (>15,000 cells/uL) & No & Yes & No & No & No & No & No & No & No & No & No \\
\hline Anemia $<11 \mathrm{~g} / \mathrm{dl}$ & Yes & Yes & No & Yes & No & No & No & No & Yes & Yes & No \\
\hline Low palatels $<150,000$ cells $/$ uL & No & No & No & No & No & No & No & No & No & No & No \\
\hline Elevated $\mathrm{C}$ reactive protein $>10$ & Yes & Yes & No & No & Yes & No & No & No & Yes & No & Yes \\
\hline Elevated Ferritin $>150 \mathrm{ng} / \mathrm{ml}$ & Yes & No & No & No & No & No & No & No & No & No & No \\
\hline $\begin{array}{c}\text { Cytolysis }(\text { ASAT }>35 \mathrm{U} / \mathrm{L} \text { or } \\
\text { ALAT }>45 \mathrm{U} / \mathrm{L})\end{array}$ & No & No & No & No & No & No & No & No & No & No & No \\
\hline $\begin{array}{c}\text { Renal dysfunction (Urea }>0.5 \mathrm{~g} / \mathrm{L} \text { or } \\
\text { Creatinin }>9 \mathrm{mg} / \mathrm{L})\end{array}$ & Yes & No & No & No & No & No & No & No & No & No & No \\
\hline
\end{tabular}

Table 5. Patients thoracic CT-Scan imaging.

\begin{tabular}{cccccccccccc}
\hline \multicolumn{1}{c}{ Imaging } \\
\hline Patient & $\mathbf{1}$ & $\mathbf{2}$ & $\mathbf{3}$ & $\mathbf{4}$ & $\mathbf{5}$ & $\mathbf{6}$ & $\mathbf{7}$ & $\mathbf{8}$ & $\mathbf{9}$ & $\mathbf{1 0}$ & $\mathbf{1 1}$ \\
\hline Thoracic CT-Scan performed & Yes & Yes & No & No & Yes & No & No & No & No & No & No \\
Typical signs of viral infection & Yes & No & - & - & Yes & - & - & - \\
\hline
\end{tabular}


taken.

\subsection{Obstetrical and Medical Outcome}

All the patients had a good evolution with disappearance of all the clinical symptoms and negativation of the RT-PCR. The average time when the PCR was positive was 17.27 days (Table 7).

Concerning newborns, the first patient showed signs of infection 20 days after her delivery thus no sample was obtained. The third, the sixth and the seventh patients are still pregnant. Samples were obtained for all the others who gave birth at our structure.

$87.5 \%$ (7 cases out of 8 ) were tested negative on all the nasopharyngeal samples. One of them was positive after contamination of the mother in the post-partum period. One case of positive SARS CoV2 RT-PCR on the placental sample was registered (out of 3); amniotic liquid was negative in 3 cases out of 3 .

Two newborns 33, 3\% (out of 6) were delivered prematurely and one of them is dead by respiratory failure.

Table 6. Patients medical treatment.

\begin{tabular}{|c|c|c|c|c|c|c|c|c|c|c|c|}
\hline \multicolumn{12}{|c|}{ Medical treatment } \\
\hline Patient & 1 & 2 & 3 & 4 & 5 & 6 & 7 & 8 & 9 & 10 & 11 \\
\hline Antibiotics & Yes & Yes & & Yes & & & & & & & No \\
\hline - Azythromycin & Yes & Yes & No & Yes & No & No & No & No & No & No & Yes \\
\hline - Ceftriaxone & No & No & & Yes & & & & & & & No \\
\hline Hydroxychloroquin & Yes & Yes & No & No & Yes & No & No & No & No & No & Yes \\
\hline Antivirals & No & No & No & Yes & No & Yes & No & No & No & No & No \\
\hline LMWH & Yes & Yes & Yes & Yes & Yes & Yes & Yes & Yes & Yes & Yes & Yes \\
\hline Oxygen support & Yes & No & No & No & Yes & No & No & No & No & No & No \\
\hline Vitamins & Yes & Yes & Yes & Yes & Yes & Yes & Yes & Yes & Yes & Yes & Yes \\
\hline Zinc & Yes & Yes & Yes & Yes & No & Yes & Yes & Yes & Yes & Yes & Yes \\
\hline
\end{tabular}

Table 7. Patients obstetrical and medical outcomes.

\begin{tabular}{|c|c|c|c|c|c|c|c|c|c|c|c|}
\hline \multicolumn{12}{|c|}{ Obstetrical and medical outcome } \\
\hline Patient & 1 & 2 & 3 & 4 & 5 & 6 & 7 & 8 & 9 & 10 & 11 \\
\hline $\begin{array}{l}\text { Indication of } \\
\text { C-section }\end{array}$ & - & $\begin{array}{c}\text { Fetal } \\
\text { distress }\end{array}$ & - & - & $\begin{array}{c}\text { Labor with } \\
\text { history of } \\
\text { early C- } \\
\text { section }\end{array}$ & - & - & $\begin{array}{c}\text { Fetal } \\
\text { distress }\end{array}$ & - & $\begin{array}{c}\text { Preecla } \\
\text { mpsia }+ \\
\text { Fetal } \\
\text { distress }\end{array}$ & - \\
\hline $\begin{array}{l}\text { Disappearence of } \\
\text { clinical symptoms }\end{array}$ & Yes & Yes & Yes & Yes & Yes & Yes & Yes & Yes & Yes & Yes & Yes \\
\hline $\begin{array}{c}\text { Duration of } \\
\text { positivity of } \\
\text { RT-PCR (in days) }\end{array}$ & 15 & 13 & 45 & 15 & 13 & 10 & 24 & 11 & 14 & 20 & 10 \\
\hline
\end{tabular}


Breastfeeding was allowed for the patients who gave birth. Breast milk was tested negatively for covid19 in 3 cases.

\section{Discussion}

\subsection{Coronaviruses and Pregnancy: Some Considerations}

Multiple studies have argued that influenza increased maternal morbidity and mortality, because of the cardiovascular and respiratory changes that occur during pregnancy, as well as the immunologic adaptations that allow a mother to tolerate an antigenically distinctive fetus.

Previous experience with coronavirus infections with MERS-CoV and SARSCov have shown that pregnant women were at more risk than general population.

For example, the SARS epidemic that occurred from November 2002 to July 2003 had caused 25\% deaths among pregnant infected women. In the first trimester 4 of 7 infected women have had miscarriages, and in the $2^{\text {nd }}$ and $3^{\text {rd }}$ trimester 2 of 5 infected women have had a neonat with intrauterine growth restriction [11].

Most of Covid-19 infections occurred during the third trimester 54.54\% (6 cases) but our study alone is not enough to affirm that pregnant woman in the third trimester is more likely to be infected

The outcomes of MERS infection included maternal deaths, premature delivery, intensive care treatment for newborns, and perinatal death [11].

Compared with SARS and MERS, COVID-19 appears to be less lethal, acknowledging the limited number of cases reported to date [12].

A joint mission by the World Health Organization consisting of 25 national and international experts travelled to the affected regions of China between 16 and 24 February 2020. They investigated pregnant women with Covid-19, and concluded that they were not at higher risk for developing severe disease due to COVID-19 [13].

\subsection{Impact on the Fetus and the Neonate}

One of the questions that are yet to be answered, is the impact of the infection on the fetus and the neonate.

It is known that vertical transmission of pathogens increases with advancing gestational age, meanwhile the severity of the transmitted infections decreases.

Nevertheless, there wasn't any proof of vertical transmission for SARS-Cov nor MERS-Cov [11]. As for SARS-CoV-2, there is no meaningful cohort following maternal infection with Covid-19 to be reported with perinatal outcomes [6], and most of these small studies show that there is currently no evidence for intrauterine infection caused by vertical transmission in women who develop COVID-19 pneumonia in late pregnancy [14]. In our study, the majority of the neonates of positive mothers were tested negative for the virus $(87.5 \%)$. One newborn was positive after birth, after his mother was infected during the post- 
partum period. There was one positive SARS-Cov2 RT-PCR on placental samples in a woman complicated with preeclampsia and fetal distress which suggests that vertical transmission is possible, and that it may cause abnormal placental perfusion wish cause the preeclampsia.

Concerning women with early stages of pregnancy, the risk of miscarriage in those affected by COVID-19 cannot be ruled out from the currently available data [12]. In our sample, we had two cases of early pregnancy (10 and 5 weeks). They did not experience any bleeding nor miscarriage.

In women affected by COVID-19 with ongoing pregnancy, surveillance for fetal growth restriction is reasonable [12].

There are case reports of preterm birth in women with COVID-19, but most of them were predominantly indications related to the viral infection [5]. There is however evidence of fetal compromise and prelabour preterm rupture of the membranes. In our study, one patient had prelabor and premature rupture of membranes at 30 weeks. Two other patients had a C-section for fetal distress but it was on a full pregnancy.

\subsection{Obstetrical Issues}

Another concern for obstetricians is finding guidelines for treatments compatible with pregnancy, for the choice of the date of delivery and delivery mode, and for neonatal care.

It is recommended that delivery mode should be determined primarily by obstetric indication if maternal illness is not severe [5] [8]. Also, the timing of delivery should be individualized based on disease severity and obstetrical complications of the pregnancy [15].

Vaginal birth is a safe delivery mode since studies have shown negative viral test results in vaginal specimen secretions [16]. Having a COVID-19 infected woman in a situation of labor is challenging. RCOG suggest to minimize the staff entering the room, and to have a continuous electronic fetal monitoring, due to the rate of fetal compromise reported. A shortening of the length of the second stage of labor with elective instrumental birth in a symptomatic woman who is becoming exhausted or hypoxic should be done if need be. The neonatal team should be given sufficient notice at the time of birth [5].

In the study of M. Ngo Dingom and al $44.4 \%$ of patients underwent an emergency cesarean. The indications for cesarean sections were fetal distress and cervical dystocia in a patient with a past history of cesarean section.

Whereas in our series, $66.6 \%$ of the patients who gave birth during the study were by $\mathrm{C}$-section and the most of the indications were fetal distress.

We believe that performing a $\mathrm{C}$-section on an infected woman who is not in labor is preferable when there is a full pregnancy, as it limits the contact with the patient. Indeed, accepting vaginal delivery involves a special monitoring of the fetal heart rate, and multiple examinations. Not to mention that there might be a complication that will require the performance of a C-section after all. 
RCOG advises that delayed cord clamping should be practiced as normal [5] whereas ISUOG suggest otherwise: they preconize a prompt clamping of the umbilical cord, although there is no sufficient evidence regarding the impact of delayed clamping on the transmission of the virus [8]. In our study, the clamping was performed as usual.

\subsection{Medical Treatments}

\subsubsection{Corticosteroids for Pulmonary Maturation}

There is no evidence to suggest that steroids for fetal lung maturation, when they would usually be offered, cause any harm in the context of COVID-19. Hence, RCOG recommend that they should be given when indicated [5].

On the other hand, ISUOG argue that steroids may worsen the clinical condition of the patient and therefore they should be used with extreme caution [8].

However, short-term (3 - 5 days) administration of methylprednisolone (1 - 2 $\mathrm{mg} / \mathrm{Kg}$ bodyweight per day) may be used to ameliorate lung inflammation and prevent acute respiratory distress syndrome [15].

We administered steroids for fetal lung maturation in two cases, when the delivery of a premature baby was inevitable (the patient with history of early Csection who had pre-labor at 30 weeks, and the patient with HELLP sd at 31 weeks). However, we did not give it for the other patients who were in the second trimester and had no obstetrical complications.

\subsubsection{Anticoagulants}

The hemodynamic changes during pregnancy make the body in a hypercoagulable state. Adding that there is emerging evidence that suggests that individuals affected by COVID-19 are also hypercoagulable, it follows that infection with COVID-19 is more likely to be increase the risk of maternal venous thromboembolism. Therefore, all pregnant women admitted with COVID-19 infection (or suspected COVID-19 infection) should receive prophylactic LMWH, unless birth is expected within 12 hours [5]. All of our patients were given LMWH, whether it was before or after childbirth.

\subsection{Antiviral Treatments}

Antiviral treatment has been routinely used to treat COVID-19 infection in China, and is also recommended for pregnant patients. The preferred drug regimen is antiproteases Lopinavir/Ritonavir as it is relatively safe in pregnancy [15].

The recommended dose is $400 \mathrm{mg}$ Lopinavir/100 mg of Ritonavir orally together with nebulized $\alpha$-interferon inhalation (5 million IU in $2 \mathrm{~mL}$ of sterile water for injection) twice a day [15].

In our study, antiviral treatments were given in $18.18 \%$ of cases ( 2 patients) with good results.

\subsection{Chloroquine and Hydroxychloroquin}

Chloroquine, a widely-used anti-malarial and autoimmune disease drug. It has 
recently been reported as a potential broad-spectrum antiviral drug, as it blocks virus infection by increasing endosomal $\mathrm{pH}$ required for virus/cell fusion, as well as interfering with the glycosylation of cellular receptors of SARS-CoV [17].

Besides its antiviral activity, chloroquine has an immune-modulating activity, which may synergistically enhance its antiviral effect in vivo [17].

This cheap and well-known drug has shown a highly effective control of 2019-nCoV infection in vitro [17].

$36.3 \%$ (4cases) of our patients have received in the post-partum a protocol with antimalarials consisting of Hydroxychloroquine (Plaquenil) $200 \mathrm{mg}$ twice a day during 10 days.

\subsection{Antibiotics}

Antibiotics are indicated if there are signs of bacterial secondary infection. The secondary infection is facilitated by lung destruction caused by the virus.

Azithromycin is a macrolide that has been used for years for treating bacterial infections. Some studies have shown that it could have an anti-viral effect, Gielen and al (2010) have shown that they could decrease the rate of replication of rhinovirus in bronchial cells by inducting interferons (IFN) by increasing the expression of Pattern Recognition Receptors (PPR) of IFN $\beta$ and IFN $22 / 3$ (Schoegler et al. 2015) [18].

In vitro studies have also shown an inhibitory effect of macrolides on the respiratory syncytial virus (RSV) in bronchial epithelial cells.

Plus, Azithromycin appears to inhibit replication of the zika virus in vitro although the mechanism of antiviral action in this case has not been studied (Retallack et al. 2016) [19].

Nevertheless, the only available data concerning the effect of azithromycin on COVID-19 are of patients also treated with hydroxychloroquine, which is not enough confirm that it is effective in treating coronavirus infection or reducing respiratory complications.

In our series, $36.3 \%$ ( 4 cases) of the patients were treated with azithromycin $500 \mathrm{mg}$ in the first day and $250 \mathrm{mg}$ from day 2 to day 7 in combination with hydroxychloroquine. Whereas in M. Ngo Dingom and al's series, Antibiotic (96\%) and anti-parasitic (88\%) treatment had been initiated in the majority of patients [20].

However, it has been mentioned that the association of azithromycin and hydroxichloroquin can cause serious cardiac adverse effects [20]. No adverse effects were noted in our patients.

\subsection{Breastfeeding}

RCOG, ISUOG, and CGNOF do not recommend separating COVID-19-affected mothers and babies [11] [13] [15]. Transmission via breastfeeding is currently regarded as improbable [14], however the main risk of breastfeeding is the close contact between the mother and her baby and therefore the passage of the virus 
via infected droplets. Hence, some precautions should be taken such as washing hands; wearing fluid-resistant surgical face-mask, and avoiding cough or sneezing. A breast-pump might be used and should be sterilized adequately before and after feeding the baby [5] [8].

\section{Conclusion}

The presentation of COVID-19 infection in pregnant women doesn't seem to be different from the general population. However, it is more challenging to manage. It can cause fetal distress as well as prelabor, early rupture of membranes or maybe preeclampsia. The obstetrical decision of fetal extraction and the delivery mode should be determined by obstetrical conditions and by the severity of the infection. Corticosteroids may be used if needed. Hydroxychloroquin is a cheap and well-known drug that can be used during pregnancy and that has shown good results in controlling the virus in vitro. Vertical transmission may be possible further studies needed, and breastfeeding should not be prohibited. These conclusions are however based on small samples, and there is an urge to conduct a study on a bigger scale to come up with clear guidelines regarding the management of pregnant women during the pandemic.

\section{Conflicts of Interest}

The authors declare no conflicts of interest regarding the publication of this paper.

\section{References}

[1] Douedi, S. and Miskoff, J. (2020) Novel Coronavirus 2019 (COVID-19): A Case Report and Review of Treatments. Medicine (Baltimore), 99, e20207. https://doi.org/10.1097/MD.0000000000020207

[2] Zhou, Y., et al. (2020) Analysis of Variation and Evolution of SARS-CoV-2 Genome. Journal of Southern Medical University, 40, 152-158.

[3] Elshafeey, F., Magdi, R., Hindi, N., et al. (2020) A Systematic Scoping Review of COVID-19 during Pregnancy and Childbirth. International Journal of Gynecology \& Obstetrics, 150, 47-52.

[4] Rasmussen, S.A., Smulian, J.C., Lednicky, J.A., Wen, T.S. and Jamieson, D.J. (2020) Coronavirus Disease 2019 (COVID-19) and Pregnancy: What Obstetricians Need to Know. American Journal of Obstetrics \& Gynecology, 222, 415-426. https://doi.org/10.1097/01.aoa.0000719440.84472.52

[5] RCOG (2020) Coronavirus (COVID-19) Infection and Pregnancy. https://www.rcog.org.uk/globalassets/documents/guidelines/2021-08-25-coronaviru s-covid-19-infection-in-pregnancy-v14.pdf

[6] Lamouroux, A., Attie-Bitach, T., Martinovic, J., Leruez-Ville, M. and Ville, Y. (2020) Evidence for and against Vertical Transmission for SARS-CoV-2 (COVID-19). American Journal of Obstetrics and Gynecology, 223, 91.e1-91.e4.

[7] Wang, W., Xu, Y., Gao, R., Lu, R., Han, K., Wu, G., et al. (2020) Detection of SARSCoV-2 in Different Types of Clinical Specimens. JAMA, 323, 1843-1844. https://jamanetwork.com/journals/jama/fullarticle/2762997 https://doi.org/10.1001/jama.2020.3786 
[8] Poon, et al. (2020) ISUOG Interim Guidance on 2019 Novel Coronavirus Infection during Pregnancy and Puerperium: Information for Healthcare Professionals. UItrasound in Obstetrics \& Gynecology, 55, 700-708. https://doi.org/10.1002/uog.22013

[9] Peyronnet, V., et al. (2020) SARS-CoV-2 Infection during Pregnancy. Information and Proposal of Management Care. CNGOF Gynécologie Obstétrique Fertilité \& Sénologie, 48, 436-443. https://doi.org/10.1016/j.gofs.2020.03.014

[10] Di Mascio, D., Khalil, A., Saccone, G., et al. (2020) Outcome of Coronavirus Spectrum Infections (SARS, MERS, COVID-19) during Pregnancy: A Systematic Review and Meta-Analysis. American Journal of Obstetrics \& Gynecology MFM, 2, Article ID: 100107. https://doi.org/10.1016/j.ajogmf.2020.100107

[11] Schwartz, D.A. (2020) An Analysis of 38 Pregnant Women with 2 COVID-19, Their Newborn Infants, and Maternal-Fetal Transmission of SARS-CoV-2: Maternal Coronavirus Infections and Pregnancy Outcomes. Archives of Pathology \& Laboratory Medicine, 144, 799-805.

[12] Mullins, E., Evans, D., Viner, R.M., O’Brien, P. and Morris, E. (2020) Coronavirus in Pregnancy and Delivery: Rapid Review. Ultrasound in Obstetrics \& Gynecology, 55, 586-592.

[13] World Health Organization. Report of the WHO-China Joint Mission on Coronavirus Disease 2019 (COVID-19).

https://www.who.int/docs/default-source/coronaviruse/who-china-joint-mission-o n-covid-19-final-report.pdf

[14] Chen, H.J. (2020) Clinical Characteristics and Intrauterine Vertical Transmission Potential of COVID-19 Infection in Nine Pregnant Women: A Retrospective Review of Medical Records. The Lancet, 395, 809-815. https://doi.org/10.1016/S0140-6736(20)30360-3

[15] Huan, L. (2020) Novel Corona Virus Disease (COVID-19) in Pregnancy: What Clinical Recommendations to Follow? AOGS, 99, 439-442. https://doi.org/10.1111/aogs.13836

[16] Wu, Y., et al. (2020) Coronavirus Disease 2019 among Pregnant Chinese Women: Case Series Data on the Safety of Vaginal Birth and Breastfeeding. BJOG, 127, 11091115. https://doi.org/10.1111/1471-0528.16276

[17] Wang, M., Cao, R., Zhang, L., et al. (2020) Remdesivir and Chloroquine Effectively Inhibit the Recently Emerged Novel Coronavirus (2019-nCoV) in Vitro. Cell Research, 30, 269-271. https://doi.org/10.1038/s41422-020-0282-0

[18] Gielen, V., Johnston, S.L. and Edwards, M.R. (2010) Azithromycin Induces AntiViral Responses in Bronchial Epithelial Cells. European Respiratory Journal, 36, 646 654. https://doi.org/10.1183/09031936.00095809

[19] Retallack, H., Di Lullo, E., Arias, C., et al. (2016) Zika Virus Cell Tropism in the Developing Human Brain and Inhibition by Azithromycin. Proceedings of the National Academy of Sciences of the United States of America, 113, 14408-14413. https://doi.org/10.1073/pnas.1618029113

[20] Ngo Dingom, M.A., Sobngwi, E., Essiben, F., Assiga, A.N., Wasnyo, Y.F., Ngate, A. Katte, J.C., Ngaha, J.Y., Nsem, P., Sone, C.E., Wandji, B., Libend, G.T., Bissemou, J.J., Eko, F.E., Fouelifack, F.Y., Ngono, G., Fouédjio, J., Tonye, R., Ongolo-Zogo, P., Fouda, P.J. and Mbu, R.E. (2020) Maternal and Fetal Outcomes of COVID-19 Pregnant Women Followed Up at a Tertiary Care Unit: A Descriptive Study. Open Journal of Obstetrics and Gynecology, 10, 1482-1491.

https://doi.org/10.4236/ojog.2020.10100135 


\section{Abbreviations}

UHC: $\quad$ University Hospital Center

SARS-COV: Severe Acute Respiratory Syndrome Coronavirus

RT-PCR: Reverse Transcriptase Polymerase Chain Reaction

CDC: $\quad$ Centers for Disease Control and Prevention

RNA: Ribonucleic Acid

ICU: Intensive Care Unit

CT: $\quad$ Computed Tomography

C-section: Cesarean-Section

ACE: Angiotensin-Converting Enzyme

MERS COV: Middle East Respiratory Syndrome-Related Coronavirus

RCOG: $\quad$ Royal College of Obstetricians and Gynecologists

ISUOG: International Society of Ultrasound in Obstetrics \& Gynecology

HELLP: Hemolysis Elevated Liver Enzymes and Low Platelets

LMWH: Low Molecular Weight Heparin

IFN: Interferons

RSV: $\quad$ Respiratory Syncytial Virus

CNGOF: Collège National des Gynécologues et Obstétriciens Français 